\title{
CORRECTION
}

\section{Correction to: Identification of OPN3 as associated with non-syndromic oligodontia in a Japanese population}

Yumi Inagaki, Takuya Ogawa, Makoto J. Tabata, Yuki Nagata (D), Ryo Watanabe, Tatsuo Kawamoto, Keiji Moriyama and Toshihiro Tanaka iD

(c) The Author(s), under exclusive licence to The Japan Society of Human Genetics 2021

Journal of Human Genetics (2022) 67:245; https://doi.org/10.1038/s10038-021-00997-9

Correction to: Journal of Human Genetics https://doi.org/10.1038/ s10038-021-00903-3, Published online 20 February 2021

It has come to the publisher and authors' attention that the conflict of interest statement in the original article was incomplete.
It should read:

Toshihiro Tanaka is Editor-in-Chief of Journal of Human Genetics. He was not involved in the peer-review or handling of the manuscript. The authors have no other competing interests to disclose. 